\title{
LUSOFONIA TRADUZIDA NA ANGLOFONIA: UMA PENETRAÇÃO DE METÁFORAS NO INSTAGRAM
}

\section{LUSOFOPHONY TRANSLATED IN ENGLISH: THE PENETRATION OF METAPHORS ON INSTAGRAM}

Carlos Henrique Teixeira de Araújo ${ }^{1}$ Christiane Pinheiro Domingues Lima ${ }^{2}$

\section{RESUMO}

Este trabalho pretende apresentar um breve panorama da interpenetração da cultura brasileira traduzida literalmente para a língua inglesa. Dessa forma, analisa-se o perfil da rede social Instagram @greengodictionary a fim de averiguar esse intercâmbio cultural e a maneira como as expressões coloquiais de língua portuguesa são traduzidas para a língua inglesa, ou seja, quais considerações são feitas e quais critérios são levados em consideração. Além do mais, investiga-se a força e o impacto sociocultural que a língua portuguesa tem na internet e nos espaços anglófonos. Mesmo que o intuito do perfil seja o caráter humorístico, pensa-se se seria possível uma tradução, ou melhor, um intercâmbio de expressões traduzidas.

\section{Palavras-Chave}

Lusofonia, Anglofonia, Instagram, Cultura

\section{Abstract}

This work presents a short overview about Brazilian cultural interpenetration translated word for word to English. Therefore, this work analyses the social media profile @greengodictionary on Instagram in order to examine the cultural exchange and the manner how the colloquial expression in Portuguese is translated to English. In other words, what kind of considerations are taken to translate those expressions and what method is taken in consideration. In addition, this work researches the power and the cultural impact that Portuguese has on Internet and in English speaking places. Even if the Instagram profile intention is the comicalness, it is asked if would be possible to translate those expressions into English, and if would be possible a cultural exchange in those translations.

\section{KEYWORDS}

Lusophony. English. Instagram. Culture.

1 Mestrando em Letras pela Universidade Presbiteriana Mackenzie.

2 Mestranda em Letras pela Universidade Presbiteriana Mackenzie. 


\section{INTRODUÇÃo}

Partir-se-á, neste artigo, de um ponto de vista linguístico - sociolinguístico-semântico-intersemiótico - e cultural a fim de analisar as expressões traduzidas ao "pé da letra" - palavra por palavra - para o inglês. Logo, a influência linguística da lusofonia nos espaços de língua inglesa - devido ao grande fluxo migratório -, da internet - a expansão e o vasto acesso a aspectos culturais de ambas as línguas - e do intercâmbio cultural, considerando-se a internet como um lugar imaterial de diáspora para o uso da língua inglesa, contudo com influências da comunidade brasileira de língua portuguesa.

Analisar-se-á as traduções feitas por um perfil do Instagram³ ${ }^{3}$ @greengodictionary ${ }^{4}$, cujo intuito é trazer humor aos seguidores da página com as versões feitas literalmente do português brasileiro ao inglês. Embora a tradução seja feita por brasileiros, deve-se ter em mente a adaptação cultura, ou seja, a verificação de expressões similares para que a cultura se encaixe em um outro idioma. Porém, o perfil @greengodictionary não considera tal noção de fidelidade tradutológica, visto que, talvez, não haja uma possibilidade de se traduzir os cinco exemplos que serão analisados.

Sendo assim, pretende-se ver a força e o impacto cultural que a língua portuguesa tem na comunidade de falantes de inglês, isto é, o efeito social e econômico.

\section{Desenvolvimento}

Segundo Oliveira, a língua portuguesa tem grande impacto na internet: "na internet, o português alcançou recentemente a cifra de 87 milhões de usuários, passando a ser, em 2010, a quinta língua mais usada na rede" (2013, p. 55). Embora os números estejam desatualizando, deve-se ter em mente a força da língua no âmbito virtual, força essa resultante do amplo acesso à tecnologia e à internet no Brasil, por exemplo.

A globalização facilitou o processo de comunicação entre vários países. Sendo assim, a "ponte" de conexão é a internet, ligando usuários em um único lugar virtual; assim, favorecendo o multiculturalismo. Mesmo com largo acessibilidade à internet, a língua mais utilizada é a inglesa, ou seja, lidera a lista de línguas nos sites e nos aplicativos. Embora não seja a primeira língua de muitos usuários, o inglês é empregado para um intercâmbio comunicação mais rápido. Dentre os idiomas mais usados, o português ocupa a quinta posição apesar de haver discrepância de acesso a internet pelos países lusófonos - Brasil e Portugal são os maiores expoentes; Moçambique e Guiné-Bissau os menores (MARTINS, 2018).

O Instagram - plataforma de publicação de fotos e de vídeos comprada pelo Facebook em 2012 e criada em 2010 por Mike Krieger e Kevin Systrom - tornou-se uma das redes sociais mais usadas ativamente no mundo. Mesmo tendo atingindo a marca de 1 bilhão de usuários em 2018, o crescimento da rede ultrapassará os $60 \%{ }^{5}$ ainda em 2019. Dessa forma, o app sozinho é grande fonte de renda: tem uma receita de aproximadamente de US\$ 14 bilhões, gerando, assim, mais visibilidade para empresas que se servem do aplicativo para obter rentabilidade com vendas e outros

\footnotetext{
3 Rede social on-line de compartilhamento de fotos e de vídeos criada em 2010 por Kevin Systrom e Mike Krieger.

4 Recentemente, durante a escrita deste artigo, a página do Instagram, originalmente @aureliusdictionary, em 30 de junho de 2019, alterou o nome de usuário para@greengodictionary.

5 https://gerenciagram.com.br/blog/post/crescimento-do-instagram/
} 
serviços. Em 2016, na média global (42\%), o Brasil teve 75\% do uso no Instagram, segundo Kantar TNS / Connected Life 6 .

Além do impacto na internet, a facilitação dos processos migratórios deu extensa contribuição ao ensino de vários idiomas. A título de exemplo, a demanda por trabalhadores qualificados para fora ou para dentro do Brasil contribui principalmente para o ensino de língua inglesa e de língua portuguesa. Logo, no século XXI, os profissionais qualificados são atraídos por melhores salários e por melhores condições de trabalho. Desde a Segunda Revolução Industrial, a imigração aos Estados Unidos deu-se por causa da reestruturação econômica pelo capitalismo

Linguístico e geograficamente, a "fuga de cérebros" coopera com o desenvolvimento da língua do país que recebe o profissional e com o desenvolvimento da língua deste também, visto que o intercâmbio cultural afeta um grupo - imigrante e nativos - nas relações intragrupal a relação que se estabelece dentro de um grupo - e intergrupal - quando pessoas de um grupo se comunicam com outros grupos.

Entre 5 e 7 milhões de falantes da língua portuguesa estão nas diásporas, especialmente nos Estados Unidos da América e no Canadá, em diferentes países europeus, no Japão, na África do Sul e na Venezuela. Essas bases geográficas são pontos de apoio e de criação de interesses para a manutenção e o ensino da língua de herança no exterior e importante razão para o intercâmbio comercial e cultural com aqueles países (OLIVEIRA, 2013, p. $55)$.

Sendo a língua inglesa, para os imigrantes brasileiros, nos Estados Unidos, uma língua estrangeira, quiçá possa ser também de acolhimento para muitos que deixam o Brasil; na internet, ela torna-se uma língua, muitas vezes, adicional, tendo em vista a afetividade no contexto virtual, acesso à cultura de massa - ou seja, foco na prática social. No espaço virtual, a aquisição do inglês pelos brasileiros pode ter vário interesse, contudo um dos principais é a compreensão de filmes, de séries e de matérias em jornais e em aplicativos sociais Sendo assim, "tenta-se adquirir a língua adicional não para servir aos interesses de outros países, mas aos próprios interesses" (LEFFA; IRALA, 2014, p. 33-34).

A anglofonia é o conjunto de países e de identidades culturais de língua inglesa. Diferentemente da lusofonia, a anglofonia é descentralizada, isto é, sem o protagonismo da ex-potencial colonial; contudo, a lusofonia, mesmo sendo descentralizada, apresenta-se dual ainda, ou seja, pautada em Portugal e no Brasil, com fraca intervenção dos outros países de língua portuguesa.

Os anglicismos - empréstimos de vocábulos da língua inglesa - são abundantes na língua portuguesa. Os neologismos por empréstimos constituem uma parte importante da cultura e da língua, visto que, talvez, o conceito ou a ideia não tenham aparecido previamente; portanto, os neologismos trazem conceitos externos, enriquecendo a língua enfocada. Eles são vocábulos de uma área, por exemplo, informática, economia, publicidade etc.

Antigamente, principalmente no romantismo literário, o uso de neologismo e de anglicismos - as variedades linguísticas em geral, caso não fosse a modalidade europeia do português - na língua portuguesa era visto de maneira negativa pelos puristas da língua. Os "americanismos" e os "brasileirismos", segundo Fiorin, tinham carga semântica pejorativa, mesmo que o período român-

6 https://br.kantar.com/tecnologia/comportamento/2016/dezembro-aumenta-uso-de-snapchat-e-instagram,-inclusive-entre-p \%C3\%BAblico-mais-velho/ 
tica preze pela edificação das particularidades da língua nacional, ou seja, uma espécie de cisão com o português de Portugal.

Contudo, a visão pura, estanque e desconexa com a realidade social da língua caí por terra, principalmente com a evolução dos estudos linguísticos - sociolinguística -, ou seja, a visão egocêntrica dá espaço à visão heterogênea, e com a evolução da tecnologia, Terceira Revolução Industrial.

A Revolução Informacional - iniciada pós-Segunda Guerra Mundial e abrangendo o período de 1950 até a atualidade - impulsionou a "migração" lexical. Neste caso, o inglês, dentre outras língua, mantém certa "soberania", visto que está, nos Estados Unidos, o grande polo tecnológico do mundo: Vale do Silício. Tal influência é tida, principalmente, por causa do aprimoramento e da descoberta da energia nuclear, da robótica, biotecnologia, etc.

Por causa da expansão virtual - isto é, internet - o inglês contém, na língua portuguesa, maior número de empréstimos. O processo de globalização, na rede, "adotou” a língua inglesa para comunicações; porém, adoção essa é decorrente da economia capitalista e do crescimento da influência desenfreada mundialmente dos Estados Unidos, exportando cultura - filmes, música, literatura - e recursos dos setores primários, secundários e terciários.

No entanto, vê-se, cotidianamente, certa inversão: a influência traduzida do português refletida no inglês. Um fato que possa ter contribuído para tal acontecimento seria a Copa do Mundo de 2014, que foi sediada no Brasil. Além de todo o preparo da infraestrutura, houve, ainda, uma preocupação linguística para o recebimento de outras nações para o evento. Mesmo o inglês sendo o grande foco linguístico para a comunicação mundial, houve traduções em lugares públicos para o espanhol e para o francês. Receptividade linguística essa que perdura até hoje nos transportes públicos, principalmente, nos avisos do metrô de São Paulo.

Além disso, na internet, o Brasil é o quatro com o maior número de usuários ${ }^{7}$, segundo dados de 2017 da Conferência das Nações Unidas sobre Comércio e Desenvolvimento, em primeiro lugar China; segundo Índia, terceiro Estados Unidos. Isso mostra que o impacto da língua portuguesa também é grande dentro do ambiente digital. Sendo assim, a cultura brasileira - mormente conhecida pelo esporte, futebol, pela comida e pela música - é compartilhada por meio de vários aplicativos na rede.

Somando-se a isso, o Brasil é o grande expoente quando se trata de criação de memes ${ }^{8}-$ "elemento que orienta a evolução cultural" segundo Higgins (2014) - quer dizer, memes são ideias, hábitos, frases de efeito, modas, etc. Dessa forma, a transmissão cultura seria idêntica a genética, segundo Dawkins (1976). Visto que essa transmissão é cultural e linguística, a ideologia é mais do que presente. Ideologia essa que, segundo Fiorin (1990, p.29), que "está contida no objeto, no social, não podendo, portanto, ser reduzida à consciência”. À vista disso, elementos, não só linguísticos, mas também socioculturais estão sendo transmitidos pelos memes.

Sendo o grande exportador de memes, o Brasil já enfrentou Portugal (primeira guerra memeal, 2016), Argentina (segunda guerra memeal, 2016-2018) e Portugal novamente (terceira guerra memeal, 2018) - as guerras foram motivadas, a primeira, pela "apropriação" dos memes brasileiro pelos

\footnotetext{
7 http://agenciabrasil.ebc.com.br/geral/noticia/2017-10/relatorio-aponta-brasil-como-quarto-pais-em-numero-de-usuarios-de-internet

8 Termo cunhado por Richard Dawkins em O gene egoísta de 1976.
} 
portugueses, a segunda, pelo pedido de vingança de Portugal a Argentina; e, a terceira, por causa de futebol. A vitória, em todas as guerras, foi do Brasil, mostra, pois, a força virtual e criativa dos usuários brasileiros.

Desta maneira, é visto como a força cultural brasileira é exercida mundialmente por meio das mídias sociais. A "força das migrações" digitais impactam o mundo, fazendo, assim, a ruína de uma hegemonia americana, até então cultural, trazendo uma heterogeneidade para o principal veículo de conexão com o mundo: a internet.

\section{Análise do corpus}

Analisar-se-ão cinco metáfrases nos posts do Instagram@greengodictionary para compreender essa interpenetração cultural e linguística do português no inglês, mais especificamente o norte-americano. Considerar-se-á que, neste contexto cultural, o humor é mais do que um efeito temporário, ou seja, instantâneo, ele pode ser uma ponte entre nações para uma compreensão mais abrangente desse processo intercultural.

A página do Twitter traz a definição do dicionário: “dictionary of Brazilian expression and cultural language in English"'. Além disso, há uma comunidade ativa de compartilhamento mantida pelo criador Matheus Diniz, assim os seguidores da página colaboram com as traduções ou com traduções inusitadas encontradas pelo Brasil ${ }^{10}$. Dessa maneira, a força cultural brasileira, seja pelo humor, seja pela seriedade, derruba os muros e os estereótipos pré-construídos do Brasil nos Estados Unidos, quiçá, no mundo.

O Brasil, no momento atual, tornou-se notícia mundialmente pela situação política e pelas polêmicas do mundo esportivo. Embora sejam de certa forma negativa para a imagem do país, a reversão essas perspectivas para um lado mais jocoso podem atenuar o impacto polêmico, ratificando o éthos expansivo e acolhedor do brasileiro construído pelo outro.

Tamanho impacto linguístico do português no inglês que a palavra "gringo" encontra-se registrada no dicionário Cambridge ${ }^{11}$. Ou seja: o uso afetivo para interpelar o estrangeiro, principalmente os falantes de língua inglesa, adentrou o léxico inglês.

Abaixo, estão expostas expressões brasileiras fossilizadas no vocabulário dos cidadãos. Alguns são mais recentes; outras, mais antigas, contudo representam bem a situação sociocultural do país.

9 Dicionário de expressões brasileiras e de cultural brasileira em inglês (tradução nossa). Frase retirada do Twitter: https://twitter. com/greengodict.

10 https://veja.abril.com.br/blog/virou-viral/pagina-viraliza-nas-redes-ao-traduzir-expressoes-brasileiras-para-o-ingles/.

11 https://dictionary.cambridge.org/pt/dicionario/ingles/gringo. 


\section{the snake is going to smoke}

[expression]

1 shit just got serious;

2 bad things are about to happen.

(a) aureliusdictionary

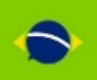

(A cobra vai fumar)

Expressão que é um ditado popular tipicamente brasileiro tendo origem na Segunda Guerra Mundial quando se conjecturava se o Brasil entraria ou não entraria na guerra. Sendo assim, a mídia brasileira dizia que seria mais fácil um cobra fumar do que a entrada do Brasil na guerra. Posteriormente, a Força Expedicionária Brasileira introduziu o lema em sua insígnia.

Tal prosopopeia, ao ser traduzida, mantém-se com seu sentido original: de uma coisa ser difícil de acontecer, mas, caso aconteça, se tornará séria. Além disso, mesmo os Estados Unidos tendo participação ativa, a gênese da expressão não seria de difícil compreensão intercultural.

Há, em inglês, outras metáforas com uso de animais, por exemplo, she is a peacock, my teacher is a dragon e he is a night owl. Dessa maneira, a transposição, se usada correntemente, não traria um impeditivo semântico aos falantes.

O sentido corrente no inglês para tal expressão é "things are going to get ugly" (a coisa vai ficar feia), ou seja, o mesmo sentido também em língua portuguesa, a expressão pode ser traduzida literalmente sem prejuízo semântico.

\section{Imagem 2}

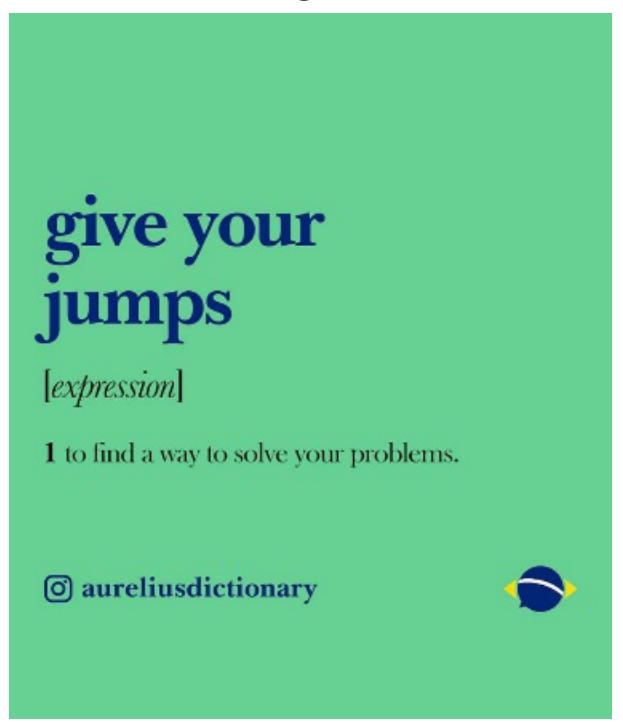

(Dá seus pulos / "se vira”) 
Expressão coloquial para resolver alguma situação dilemática. A frase pode ter um sentido meritocrático com um tom imperativo. Contudo, em inglês, o sentido da expressão com o mesmo sentido contém um tom bem mais formal "to manage (on your own)". Além disso, a expressão traz em si a brasilidade, isto é, o sentido de que o brasileiro sempre acha um jeito de "se virar" em situações fáceis ou difíceis, sendo assim, o “jeitinho” brasileiro.

Os Estados Unidos por serem uma nação altamente individual e focarem no trabalho árduo desde a colonização puritana, esse sentido mais "meritocrático" expresso na frase talvez não tivesse impeditivos para a penetração cultural.

Contudo, os sentidos atribuídos à frase, no Brasil, dependendo do contexto, podem, na maioria das vezes, ter acepção jocosa e humorística, já que, quotidianamente, os brasileiros precisam improvisar soluções para situações dilemáticas, sendo da criatividade até a ilegalidade.

Imagem 3

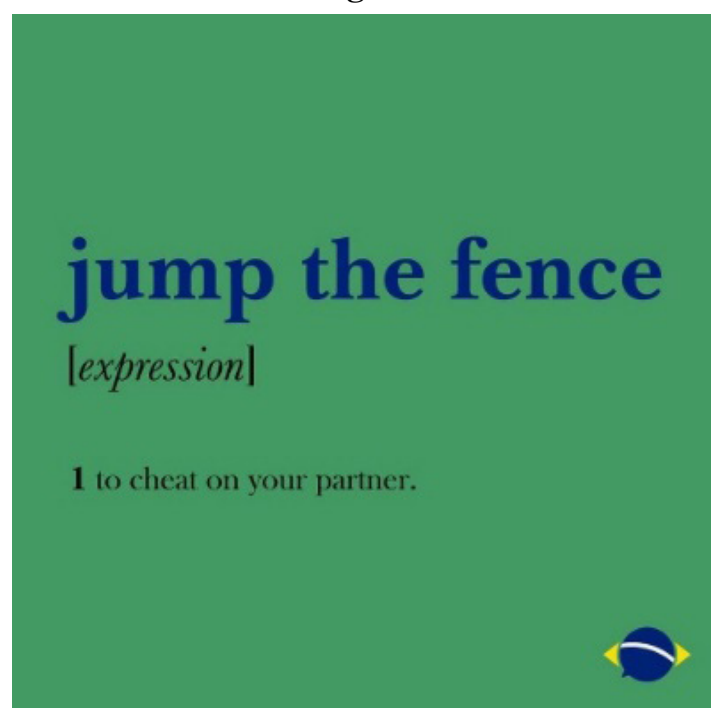

(Pular a cerca)

Origem duvidosa, porém, em senso comum, diz-se que é uma alusão ao boi que pula a cerca da fazenda para ir atrás da vaca. Expressão coloquial bastante usada para traição em relacionamentos ou, num sentido mais amplo, traição de qualquer esfera.

Pensando em aspectos culturais, a penetração linguística desta expressão não seja um empecilho cultural. Hipoteticamente, a assimilação dessa frase poderia ser mais aceita para os americanos visto que o processo de acomodação lexical da expressão não seria um alien para os padrões arquitetônicos das cidades dos Estados Unidos, onde geralmente há casas, nos subúrbios, separadas de outras por cercas.

Em inglês, a expressão é utilizada é "to fool around", ou "to cheat on", sem traduções feitas ao pé da letras para o português. Sendo a segunda frase mais passível de compreensão para o brasileiro ao tentar entendê-la. 


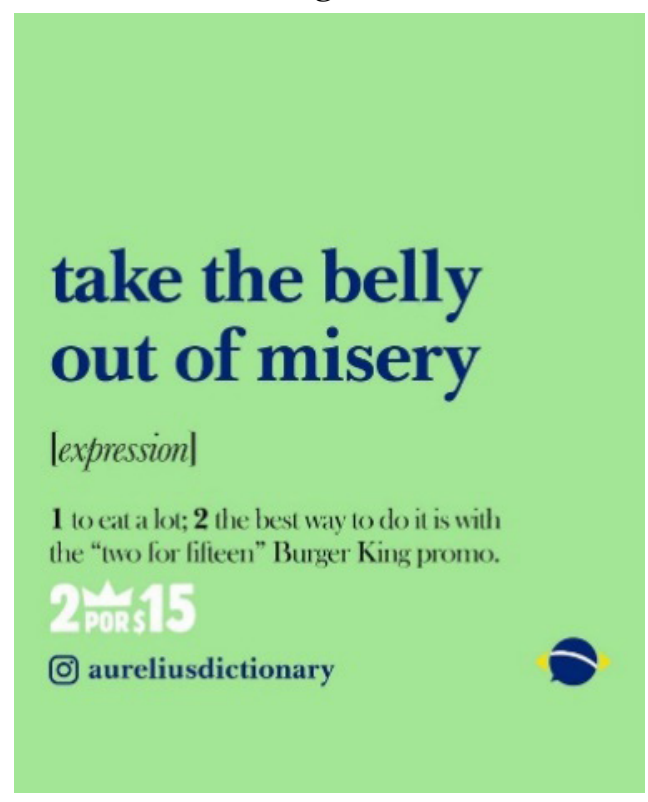

(Tirar a barriga da miséria)

A expressão exposta acima, além de ter um viés jocoso, pode trazer uma crítica social por detrás. A frase fossilizada pode ter um grito de protesto. Contudo, está, nesta definição, sendo usada como uma propaganda da rede Burger King: ou seja, o viés persuasivo - a função conativa - é bem marcante para fazer o receptor associar a saciação com um produto específico, neste caso, o hambúrguer. A interculturalidade está evidente na escolha da rede de restaurantes de origem norte-americana. Sendo assim, a adaptação, ou melhor, a tradução do português para o inglês, deve-se associar com um estabelecimento também de origem estrangeira, mantendo assim a isotopia: expressão em inglês mais estabelecimento em inglês, contudo sentido tipicamente brasileiro.

A perspectiva local - a expressão em si - se entendida com uma ressignificação de uma chaga social: fome, pode representar e encapsular um problema global, por exemplo, visto que os Estados Unidos são uma potencial econômica.

A expressão empregada em inglês para o sentido é "to eat your fill" (comer até se encher), frase essa com essência vista na língua portuguesa. Sendo assim, algumas expressões possuem representações em ambos os idiomas, por causa do grau de transparência

Imagem 5

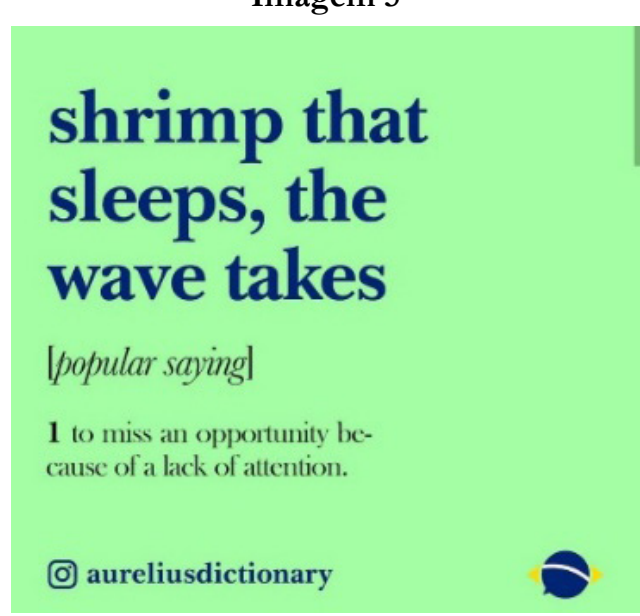

(Camarão que dorme a onda leva) 
Expressão presente na música de Arlindo Cruz, Jesse Silva e Laudeni Casemiro, cantada por Beth Carvalho e Zeca Pagodinho, tem o sentido de "dar bobeira", "se distrair" e "agir sem prudência".

Porventura, expressão com maior grau de opacidade para uma aquisição pelo norte-americano. Existem praias nos Estados Unidos, porém o Brasil possui outras idiossincrasias em relação ao comportamento à beira-mar.

Por exemplo, é notória a fama dos biquínis brasileiros e da abundância de comida levada pelas pessoas, devido à economia. Além do questão polêmica do vestuário feminino, a sunga - vestuário unânime pelo brasileiros - é um dilema para os americanos. Os homens brasileiros aderem à indumentária em $90 \%$; porém, os americanos aderem em $48 \%{ }^{12}$ segundo relatório Flip Flop. Soma-se a isso o consumo de bebidas alcoólicas e de comidas, que são raras nas praias americanas.

Não há um sentido paralelo de tal locução do português ao inglês. A tradução, assim, deve ser feita pelo acepção genérica do termo. Em inglês, o frase corrente é "up for grabs", "mess up" ou "drop the ball", todas com essência coloquial. Sua lexicalização pelos americanos poderia penetrar no falar por meio de uma grande insistência, ou seja, caso seja legitimada por uma ampla comunidade.

A linguística cognitiva, por meio do pensamento corporificado ou pelo princípio de projeção, e a semântica, por meio dos esquemas metafóricos, poderiam da conta dos processos de permutabilidade, junto, logicamente, com os estudos culturais e de tradução.

\section{Conclusão}

O mundo não passa de empréstimos culturais e colagem de discursos (MATTELART; NEVEU, 2004). Além disso, há uma metáfora usada pelos autores que pode encapsular o sentido dessas interculturalidades: o turista passa a ser um viajante que explora e decodifica a cultura local. Viagem essa que está mais facilidade, visto que a internet diminui virtualmente as fronteiras do conhecimento.

Nesse sentido, os estudos culturais nos Estados Unidos sejam e tenham um grande impacto visto que "a crescente importância do cultural como objeto de pesquisa e de formação universitária deveria também, muito simplesmente, do lugar tomado pela produção de bens culturais" (MATTELART; NEVEU, 2004, p 133).

A cultura de massa, neste caso presente no Instagram analisado, expressa uma valorização do paradigma atual, ou seja, das implicações que a sociedade contemporânea pode contribuir para seu melhor entendimento da questão do homem pós-moderno.

As expressões podem não ser fiéis às representações culturais americanas, contudo são propositais. O Brasil, ou melhor, a língua portuguesa absorveu grande número de anglicismo ao longo das revoluções tecnológicas, seja traduzindo, seja mantendo o original.

"O inglês, bem mais que o francês ou o alemão, constitui a língua dos intercâmbios acadêmicos internacionais (MATTELART; NEVEU, 2004, p 131). Pode-se acrescentar a isso os intercâmbios culturais, sendo assim, a língua portuguesa quer fazer-se presente na anglofonia seja por fatores migratórios, seja por questões de potência numérica na internet, seja para um homogeneização ou uma harmonia no poderia americano perante o mundo virtual.

12 https://viajando.expedia.com.br/estudo-da-expedia-revela-quais-sao-os-comportamentos-que-mais-irritam-os-brasileiros-na-praia/. Acesso em: 08 jun. 2019. 
“O mundo contemporâneo é essencialmente multicultural” (MARTINS, 2018, p, 7) visto que material ou virtualmente trocas culturais ocorrem em escala global: apropriações do material da modernidade, de maneira lenta ou rápida. Para Arjun Appadurai, a globalização é um desajuste de áreas como a cultura, a economia e a política, sendo assim, os estados-nação vão formando um mosaico cultural, absorvendo aspectos positivos ou negativos de outros lugares.

Essas traduções interculturais ou interlinguais são importantes nesses meios de comunicação de massa para que as barreiras da xenofobia e do preconceito sejam mitigadas; permitindo, assim, uma reavaliação os estereótipos negativos reproduzidos na pós-modernidade. É sabido que algumas expressões culturais podem estar no plano do intraduzível, contudo o interessante do perfil do Instagram analisado é a possibilidade de despertar a curiosidade pelo país e pelo idioma. Quiçá o multiculturalismo esteja encurtando o relativismo linguístico, "a língua é um fator de identificação cultural", segundo Mateus (2001, p. 1).

\section{REFERÊNCIAS}

ALVES, I. M. Neologismo: criação lexical. 2. ed. São Paulo: Ática, 2002.

ARROJO, R. Oficina de tradução: a teoria na prática. 4. ed., São Paulo: Ática, 2013.

BASTOS, N. B. Língua portuguesa: reflexões lusófonas. São Paulo: Editora PUC,

BATISTA, R. O. A linguagem e os falantes: ideias linguísticas e sua história. São Paulo: Editora Mackenzie, 2017.

CALVET, L.-J. Sociolinguística: uma introdução crítica. São Paulo: Parábola Editorial, 2002.

CASTILHO, A. T.; ELIAS, V. M. Pequena gramática. São Paulo: Contexto, 2017.

CIEGLINSKI, A. Relatório aponta Brasil como quatro país em número de usuários de internet. Agência Brasil. 2017. http://bit.ly/3681n5R. Acesso em 01 jun. 2019.

COUTO, M. E se Obama fosse africano?: e outras intervenções. São Paulo: Companhia das Letras, 2011

FIORIN, J. L. (Org.). Novos caminhos da linguística. São Paulo: Contexto, 2017.

Linguagem e ideologia. 2. ed. São Paulo: Ática, 1990.

GLOBO. O livro da sociologia. São Paulo: Globo Livros, 2015.

LEFFA, V. J.; IRALA, V. B. O ensino de outra(s) língua(s) na contemporaneidade: questões conceituais e metodológicas. In: LEFFA, V. J.; IRALA, V. B. (Orgs.). Uma espiadinha na sala de aula: ensinando línguas adicionais no Brasil. Pelotas: Educat, 2014, p. 21-48.

LOPES, L. P. M. (Org.). O português no século XXI: cenário geopolítico e sociolinguístico. São Paulo: Parábola, 2013.

MATEUS, M. H. M. Se a língua é um fator de identificação cultural, como se compreenda que um língua viva em diferentes culturas? Disponível em http://bit.ly/2RAiLLa. Acesso em: 08 jun. 2019.

MARTELOTTA, M. E. (Org.). Manual de linguística. 2. ed. São Paulo: Contexto, 2012.

MARTINS, M. L. A lusofonia no contexto das identidades transnacionais e transcontinentais. Letrônica, Porto Alegre, v. 11, n. 1, 2018, p. 3-11.

MOURA, G. Crescimento do Instagram ultrapassará os $60 \%$ neste ano; saiba como aproveitar desta ascensão. Gerenciafram. 2019. disponível em http://bit.ly/2G8kjXm. Acesso em: 08 mai. 2019.

NEVEU, E. Introdução aos estudos culturais. São Paulo: Parábola Editorial, 2004.

PATITUNDA, R. Aumenta uso de Snapchat e Instagram. Inclusive entre o público mais velho. Kantar. 2016. disponívem em http://bit.ly/38jWvMh. Acesso em: 08 mai. 2019.

POSSENTI, S. Humor, língua e discurso. São Paulo: Contexto, 2010.

TARALLO, F. A pesquisa sociolinguística. 7. ed. São Paulo: Ática, 2001.

VERDASCA, J. A língua de Camões: do homo sapiens à língua portuguesa. São Paulo: IBRASA, 1995. 